\title{
EXPERIMENTAL STUDY ON PRESSURE SENSITIVE PROPERTIES OF COPPER CONTAMINATED SOIL SOLIDIFIED BY MODIFIED RED MUD
}

\author{
Keyu SHEN ${ }^{1,2^{*}}$ \\ ${ }^{1}$ China University of Mining and Technology, Xuzhou, China \\ ${ }^{2}$ Royal Melbourne Institute of Technology, Melbourne, Australia
}

Received 09 September 2018; accepted 21 December 2018

\begin{abstract}
As a static method for testing pollution and strength of soil, the resistivity method has been used by many scholars, whereas few studies have been carried out on dynamic deformation monitoring by this method. To study the pressure sensitive properties of copper contaminated soils solidified by modified red mud, a series of unconfined compression tests were conducted. The compressive stress, strain and electrical resistivity in whole process were determined. Relationship between the resistivity and the parameters including stress, strain, red mud content, copper content, and curing age were analysed. Then the mechanism of electrical resistivity is revealed. Results indicate the stress-resistivity change rate follows the same trend as the stress-strain curve. The resistivity change rate follows the same rule as the strain change, indicating that the electrical resistivity can reflect the strain indirectly. The higher red mud content is, the better pressure sensitive properties of solidified soil is. A proper amount of copper can improve the pressure sensitivity of solidified soil, while excessive copper ions can reduce pressure sensitivity of solidified soil. These changes can be attributed to the pore water, iron oxide in red mud, tunnel conductive effect and conductivity percolation.
\end{abstract}

Keywords: modified red mud, solidified soil, copper contaminated soil, pressure sensitive properties, electrical resistivity.

\section{Introduction}

Red mud is a solid waste discharged from alumina production. At present, most of the alumina factories dispose red mud by storing it at dam construction sites. Large amount of red mud not only occupies large area of land, but also causes the soil salinization and groundwater pollution in the surrounding area (Wansom, Kidner, \& Woo, 2006). As the red mud has high alkalinity, large specific surface area and good absorbability, it can be applied to the solidification of heavy metal contaminated soil (Wansom et al., 2006; Song, Suo, Dong, \& Chen, 2018). Moreover, the reactivity of red mud has a great influence on the curing effect (Abdulvaliyev, Akcil, \& Gladyshev, 2015). As the red mud produced by the Bayer process after many washing cycles, settling and filtering, most of minerals in its particles have lost their reactivity. Only some of them are potentially active. So how to improve and stimulate the reactivity of red mud attracts extensive attentions. Red mud was modified by Sujana, Thakur, and Acharya (1996) using calcination, by Alp and Goral (2003) using acid treatment, by Sushil and Batra (2012) using the alkali additive, and by Ordóñez, Sastre, and Díez (2001) combining acid solution, ammonia water and calcination. It was found that the red mud became more active after modifications.
Pressure sensitivity defines the resistivity change rate of the sensitive material with the change in stress and strain. By measuring the change of material resistivity, the changes of stress, strain and damage of the internal structure can be correlated (Borra, Mermans, \& Blanpain, 2016; Gamaletsos et al., 2016; Lockwood, Mortimer, and Stewart, 2014; Davris, Balomenos, \& Panias, 2016). Liu (2016) compared the pressure sensitivity of cement paste test blocks made of carbon fiber, carbon nanotubes and graphene, and found that the pressure sensitivity of cement test blocks made of carbon nanotubes have the best effect. Zhao, Zhuang, and Jiyang (2014) added steel yarn and iron ore sand into the cement system to prepare cement-based composites, and pointed out that the cementbased composites with steel yarn and iron ore had good compression sensitivity. Li, Wang, and Zhao (2007) treated carbon nanotubes with $\mathrm{H}_{2} \mathrm{SO}_{4}$ and $\mathrm{HNO}_{3}$ mixed solutions and evenly dispersed them into cement slurry. The results showed that the compression sensitivity of the composite material was significantly improved. However, there are few reports on the pressure sensitivity of copper contaminated soils solidified by modified red mud.

In this paper, the activity of red mud is excited by calcium oxide, and the modified red mud treated copper

${ }^{*}$ Corresponding author. E-mail: tyshenkeyu@126.com 
contaminated soils are taken as the research object. The change in stress, strain, resistivity and other parameters during the whole process are tested till compression failure in uniaxial compressive condition. The effects on the pressure sensitivity for the solidified soil of red mud content, the content of copper and the curing age are studied. Finally, the change mechanism of the pressure sensitivity is systematically analysed. The experiment aims to study the conductivity of red mud treated copper contaminated soil, and reveal the pressure sensitive properties without adding any conductive materials. This study would provide an experimental reference for the field sensitivity monitoring in the solidification engineering at heavy metal contaminated sites.

\section{Test materials}

\subsection{Soils}

Typical loess in Dongshan area, Taiyuan city, Shanxi province was used in current tests. The basic physical indexes are shown in Table 1. The chemical components are $\mathrm{SiO}_{2}, \mathrm{Al}_{2} \mathrm{O}_{3}, \mathrm{CaO}, \mathrm{Fe}_{2} \mathrm{O}_{3}$, with the maximum content of $\mathrm{SiO}_{2}$ of $58.88 \%$, and a small amount of other components such as $\mathrm{MgO}, \mathrm{K}_{2} \mathrm{O}, \mathrm{Na}_{2} \mathrm{O}$, as well as the specific content shown in Table 2. A $1.25 \mathrm{~mm}$ sieve was used to determine the particle size distribution of loess, as shown in Figure 1. The microscopic morphology of the loess particles shown in Figure 2, mainly composed of large block of quartz and some zeolite, mica, chlorite and feldspar. The particles are dispersed and minerals are distributed randomly. The small particles are attached to the surface of the large particles to connect the particles and fill pores.

Table 1. Basic physical indexes of Loess

\begin{tabular}{|c|c|c|c|}
\hline $\begin{array}{c}\text { Soil particle } \\
\text { proportion } \\
G_{S}\end{array}$ & $\begin{array}{c}\text { Maximum } \\
\text { dry density } \\
\left(\mathrm{g} \cdot \mathrm{cm}^{-3}\right)\end{array}$ & $\begin{array}{c}\text { Optimal } \\
\text { water content } \\
(\%)\end{array}$ & $\begin{array}{c}\text { Liquid } \\
\text { limit } \\
(\%)\end{array}$ \\
\hline 2.7 & 1.77 & 16.7 & 23.3 \\
\hline $\begin{array}{c}\text { Plastic } \\
\text { limit } \\
(\%)\end{array}$ & $\begin{array}{c}\text { Plastic } \\
\text { index } \\
I_{\mathrm{P}}\end{array}$ & $\begin{array}{c}\text { Collapsibility } \\
\text { coefficient } \\
\Delta_{\mathrm{S}}\end{array}$ & \\
\hline 15.1 & 8.2 & 0.019 & \\
\hline
\end{tabular}

Table 2. Main chemical components of Loess

\begin{tabular}{|l|c|c|c|c|c|c|}
\hline $\begin{array}{c}\text { Chemical } \\
\text { composition }\end{array}$ & $\mathrm{SiO}_{2}$ & $\mathrm{Al}_{2} \mathrm{O}_{3}$ & $\mathrm{CaO}$ & $\mathrm{TFe}_{2} \mathrm{O}_{3}$ & $\mathrm{MgO}$ & $\mathrm{K}_{2} \mathrm{O}$ \\
\hline $\begin{array}{l}\text { Percentage } \\
\text { content (\%) }\end{array}$ & 58.88 & 11.75 & 7.98 & 4.54 & 2.05 & 2.18 \\
\hline $\begin{array}{l}\text { Chemical } \\
\text { composition }\end{array}$ & $\mathrm{Na}_{2} \mathrm{O}$ & $\mathrm{S}$ & $\mathrm{TiO}_{2}$ & $\mathrm{C}$ & Others & \\
\hline $\begin{array}{l}\text { Percentage } \\
\text { content (\%) }\end{array}$ & 1.70 & 0.012 & 0.60 & 2.00 & 8.31 & \\
\hline
\end{tabular}

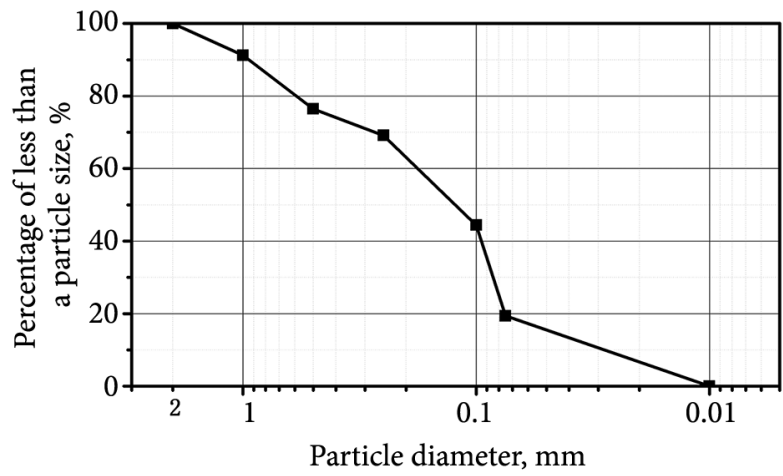

Figure 1. Particle sized of loess

\subsection{Red mud}

The red mud from alumina production was produced by Bayer process in Shanxi Liulin aluminum plant. From Table 3, the chemical components of red mud are $\mathrm{SiO}_{2}$, $\mathrm{Al}_{2} \mathrm{O}_{3}, \mathrm{CaO}, \mathrm{TFe}_{2} \mathrm{O}_{3}$, and small amount of $\mathrm{MgO}, \mathrm{Na}_{2} \mathrm{O}$, $\mathrm{K}_{2} \mathrm{O}$. Individual red mud particles are easy to form bigger particulates due to their fine particle size and superposition. The SEM microscopic morphology of red mud particles is shown in Figure 3.

Table 3. Main chemical components of red mud

\begin{tabular}{|l|c|c|c|c|c|c|}
\hline $\begin{array}{c}\text { Chemical } \\
\text { composition }\end{array}$ & $\mathrm{SiO}_{2}$ & $\mathrm{Al}_{2} \mathrm{O}_{3}$ & $\mathrm{CaO}$ & $\mathrm{TFe}_{2} \mathrm{O}_{3}$ & $\mathrm{MgO}$ & $\mathrm{K}_{2} \mathrm{O}$ \\
\hline $\begin{array}{l}\text { Percentage } \\
\text { content (\%) }\end{array}$ & 20.17 & 24.34 & 18.26 & 9.40 & 1.26 & 0.64 \\
\hline $\begin{array}{l}\text { Chemical } \\
\text { composition }\end{array}$ & $\mathrm{Na}_{2} \mathrm{O}$ & $\mathrm{S}$ & $\mathrm{TiO}_{2}$ & $\mathrm{C}$ & Others & \\
\hline $\begin{array}{l}\text { Percentage } \\
\text { content (\%) }\end{array}$ & 9.61 & 0.19 & 3.56 & 1.06 & 11.51 & \\
\hline
\end{tabular}

The main heavy metal ions, leaching concentration and the limit of red mud are shown in Table 4. The concentration of heavy metals in leaching solution is far less than the limit, according to the "Identification standards for hazardous wastes-Identification for extraction toxicity"(GB 5085.3-2007). The particle size distribution curve of red mud tested after grinding through $2.5 \mathrm{~mm}$ sieve is shown in Figure 4, which indicates $97.3 \%$ of the particle size is within the range of $0.1-1 \mathrm{~mm}$.

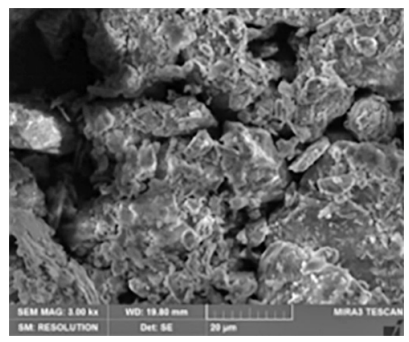

a) $3000 \times$



b) $10000 \times$
Figure 2. Microscopic morphology of loess particles 

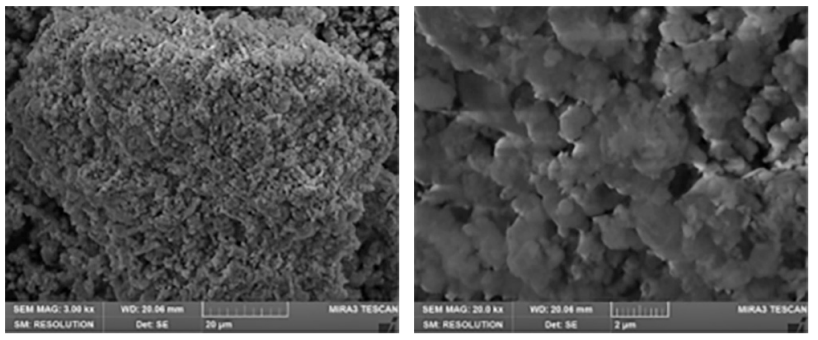

a) $3000 \times$

b) $10000 \times$

Figure 3. Microscopic morphology of red mud particles

\subsection{Other materials}

In this study, 42.5\# ordinary Portland cement was used. Its main chemical compositions are shown in Table 5. Copper pollution is simulated by $\mathrm{Cu}\left(\mathrm{NO}_{3}\right)_{2} \cdot 3 \mathrm{H}_{2} \mathrm{O}$. Tap water was used during the preparations of the samples.

\section{Experimental scheme}

The experimental scheme is shown in Table 6. The ratio of the cement and soil is $1: 10$ by weight. The proportion of the red mud and $\mathrm{CaO}$ is 3:1 by weight. The content of red mud is expressed by $C_{\mathrm{RM}}$. A cubic block with length of $70.7 \mathrm{~mm}$ was prepared according to the "Standard for test method of performance on building mortar" (JGJ/T702009), and three samples were prepared in each group. After $24 \mathrm{~h}$ curing at temperature of $20 \pm 5^{\circ} \mathrm{C}$, the samples were then cured in a curing box with the temperature of $20 \pm 2{ }^{\circ} \mathrm{C}$ and relative humidity of above $90 \%$ for $7 \mathrm{~d}, 14 \mathrm{~d}$, $28 \mathrm{~d}, 60 \mathrm{~d}$ and $90 \mathrm{~d}$, respectively. Unconfined compressive

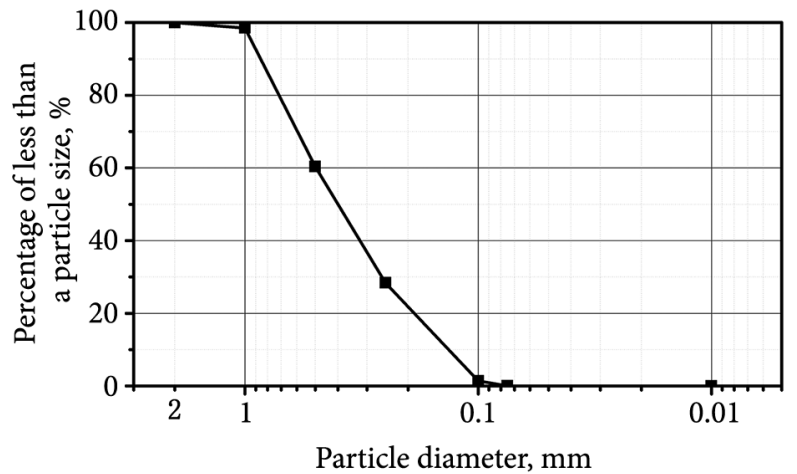

Figure 4. Particle size of red mud

strength tests were conducted with the displacement rate of $0.03 \mathrm{~mm} \cdot \mathrm{s}^{-1}$ by using computer-controlled electronic universal testing machine until the failure of the specimens. The changes in stress, strain, resistivity was recorded during the test. The resistivity was measured by alternating current method with $50 \mathrm{kHz}$ frequency.

Contaminated soils were made with loess and $\mathrm{Cu}\left(\mathrm{NO}_{3}\right)_{2} \cdot 3 \mathrm{H}_{2} \mathrm{O}$. According to the actual contaminated site, the upper limit content of copper ion was set to be $2.5 \%$. Contaminated soils were divided into 8 proportions according to $C_{\mathrm{Cu}}$ - the proportion of $\mathrm{Cu}^{2+}$ in the loess. The specific proportions were shown in Table 7. In the previous experiment, it was found that when $\mathrm{C}_{\mathrm{Cu}} \geq 1 \%$, the contaminated soils could not be solidified by pure cement, therefore the selection of the proportions of $\mathrm{Cu}^{2+}$ in the pure cement were within $0-0.75 \%$, and in red mud within $0-2.5 \%$.

Table 4. Leaching toxicity of excess heavy metals in red mud

\begin{tabular}{|l|c|c|c|c|c|c|c|c|}
\hline \multicolumn{1}{|c|}{ Heavy metal } & $\mathrm{Pb}$ & $\mathrm{Cr}$ & $\mathrm{Cd}$ & $\mathrm{Ni}$ & $\mathrm{Be}$ & $\mathrm{As}$ & $\mathrm{Hg}$ & $\mathrm{F}$ \\
\hline Content in red mud $\left(\mathrm{mg} \cdot \mathrm{kg}^{-1}\right)$ & 86 & 240 & 6 & 64 & 4.97 & 8.88 & 0.12 & 1275 \\
\hline Concentration limit $\left(\mathrm{mg} \cdot \mathrm{kg}^{-1}\right)$ & 5 & 15 & 1 & 5 & 0.02 & 5 & 0.1 & 100 \\
\hline Leaching concentration $\left(\mathrm{mg} \cdot \mathrm{kg}^{-1}\right)$ & $1.8 \mathrm{e}^{-3}$ & $1.34 \mathrm{e}^{-2}$ & $1.66 \mathrm{e}^{-4}$ & $3.26 \mathrm{e}^{-4}$ & $8.4 \mathrm{e}^{-5}$ & $2.3 \mathrm{e}^{-2}$ & 0.03 & 7.86 \\
\hline
\end{tabular}

Table 5. Main chemical components of cement

\begin{tabular}{|l|c|c|c|c|c|}
\hline Chemical composition & $\mathrm{SiO}_{2}$ & $\mathrm{Al}_{2} \mathrm{O}_{3}$ & $\mathrm{CaO}$ & $\mathrm{TFe}_{2} \mathrm{O}_{3}$ & $\mathrm{MgO}$ \\
\hline Percentage content (\%) & 20.96 & 4.98 & 64.03 & 3.22 & 1.30 \\
\hline Chemical composition & $\mathrm{K}_{2} \mathrm{O}$ & $\mathrm{Na}_{2} \mathrm{O}$ & $\mathrm{S}$ & Others & \\
\hline Percentage content (\%) & 0.55 & 0.07 & 2.60 & 2.29 & \\
\hline
\end{tabular}

Table 6. Test scheme

\begin{tabular}{|l|l|c|c|c|c|c|}
\hline \multicolumn{2}{|c|}{ Curing scheme } & 1 & 2 & 3 & 4 & 5 \\
\hline \multirow{4}{*}{ Curing agent (\%) } & Red mud & 0 & 15 & 30 & 45 & 60 \\
\cline { 2 - 8 } & $\mathrm{CaO}$ & 0 & 5 & 10 & 15 & 20 \\
\cline { 2 - 8 } & Cement & 10 & 10 & 10 & 100 & 10 \\
\hline Loess & 100 & 100 & 29 & 30 & 31 \\
\hline \multicolumn{2}{l|l}{ Water content (\%) } & 27 & 28 & 100 & & 100 \\
\hline
\end{tabular}


Table 7. Cu content in solidified soil

\begin{tabular}{|l|l|l|l|l|l|l|l|l|}
\hline \multicolumn{10}{|c|}{ Content of $\mathrm{Cu}^{2+}$ in soil } \\
\hline Proportion (\%) & 0 & 0.05 & 0.1 & 0.25 & 0.5 & 0.75 & 1 & 2.5 \\
\hline
\end{tabular}

\section{Study on the pressure sensitivity of contaminated solidified soil}

\subsection{Study on stress and strain relation and stress and resistivity change rate relation}

Figure 5 presents typical stress-strain curves and stressresistivity change rate curves when $C_{\mathrm{Cu}}=0$ and $0.75 \%$ after samples curing for 28 days. The resistivity change rate in the diagram is defined as:

$$
\Delta \rho / \rho_{0}=\left(\rho-\rho_{0}\right) / \rho_{0},
$$

where $\Delta \rho$ is the resistivity difference value $\Omega \cdot m ; \rho$ is the instantaneous resistivity $\Omega \cdot \mathrm{m} ; \rho_{0}$ is the initial resistivity $\Omega \cdot \mathrm{m}$.

Comparing (a)(b) with (c)(d) in Figure 5, it is found that the solidified soil at the initial stage of loading is in the elastic stage. The initial cracks and holes in the test block were squeezed, and the resistivity change rate is basically in the state of linear reduction. Continuous



a) $C_{\mathrm{Cu}}=0$ Stress-strain curve

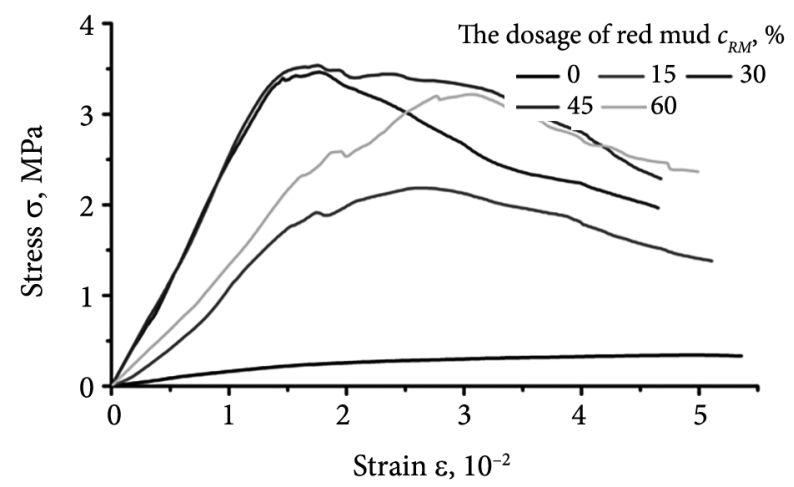

c) $C_{\mathrm{Cu}}=0.75 \%$ Stress-strain curve compression of the specimen made the stress concentration occur at the original cracks. The interfacial cracks became larger, and the vertical stress quickly increased to the yield stage in the uniaxial compression condition. The crack of the specimen became even larger at the same time, the test block is in the unstable state with the fast cracking development. While the resistivity change rate is in a stable decreasing stage. When the stress-strain curve passes the inflection point, the vertical deformation of the test block increased and the crack completely penetrated. In this process, the resistivity change rate decreases, but the rate of reduction decreases. Figure 6 shows the block photos of the red mud solidified soil with $C_{\mathrm{Cu}}=2.5 \%$ and $C_{\mathrm{RM}}=30 \%$ at Day 28. It is seen the crack of the specimen with the pressure increase gradually expands. The first crack appears at the end of the elastic phase. The crack rapidly extends to the final length after the specimen reaches the peak stress. The specimen reaches the completely cracking state after the compression test completed.

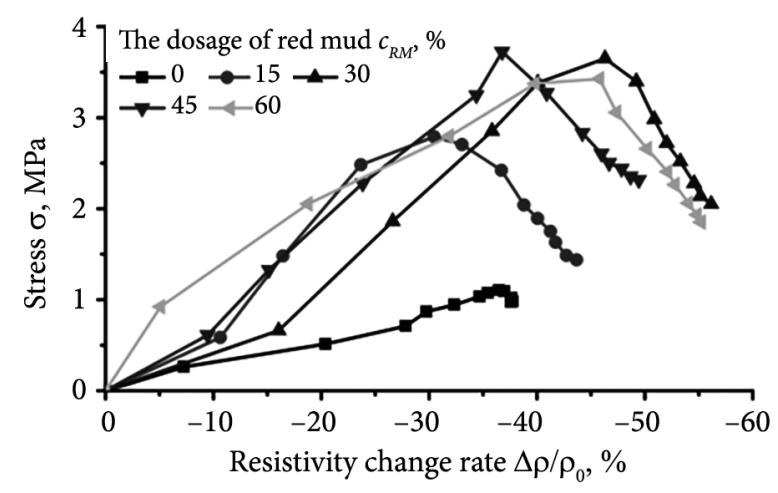

b) $C_{\mathrm{Cu}}=0$ Stress-resistivity change rate curve

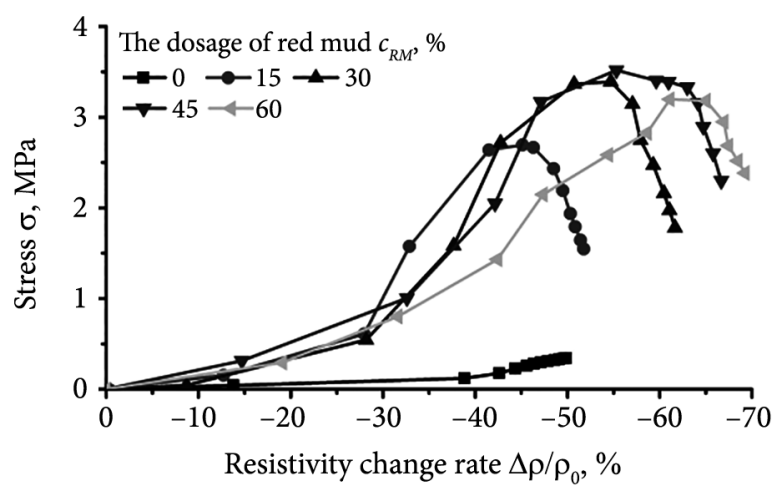

d) $C_{\mathrm{Cu}}=0.75 \%$ Stress-resistivity change rate curve

Figure 5. Curves of stress-strain, and stress-resistivity change rate of $28 \mathrm{~d}$ solidified soil 

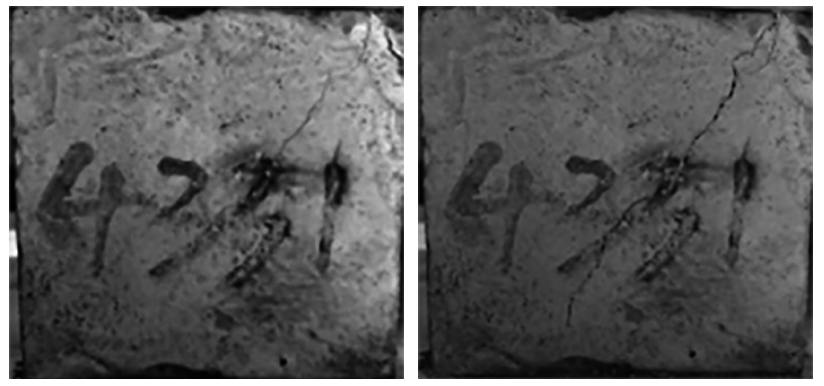

a) $\sigma=2.81 \mathrm{MPa}$

b) $\sigma=3.49 \mathrm{MPa}$

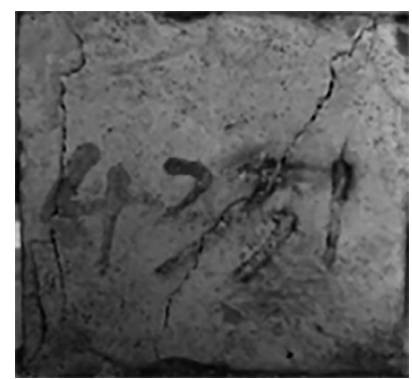

c) $\sigma=1.53 \mathrm{MPa}$

Figure 6. Optical photograph of $28 \mathrm{~d}$ solidified soil test block in unconfined compression condition with

$C_{\mathrm{Cu}}=2.5 \%$ and $C_{\mathrm{RM}}=30 \%$



a) $C_{\mathrm{Cu}}=0$

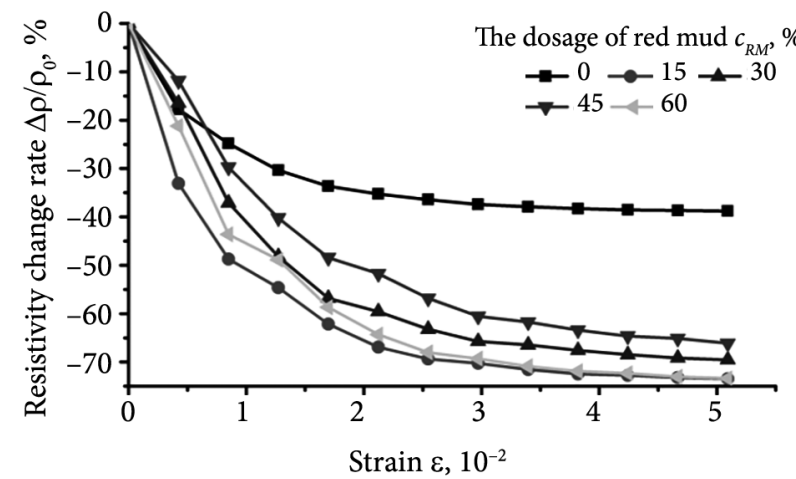

c) $C_{\mathrm{Cu}}=0.5 \%$

\subsection{Relationship between the pressure sensitivity and the red mud content}

Figure 7 presents the relationship of resistivity change rate and strain with different red mud content for the solidified soil after 28 days. When $C_{\mathrm{Cu}}>1 \%$, soil solidified by pure cement cannot be formed, so four samples with $C_{\mathrm{Cu}}=0$, $0.1 \%, 0.5 \%, 1 \%$ were selected respectively for analysis.

The resistivity change rate of solidified soil gradually decreases with the increase of strain for all samples with different contents of red mud. In the initial stage of strain increase, resistivity change rate decreases sharply, while the resistivity change rate tends to be stable with the strain increases later. The change of the resistivity curve tends to be gentle, which is basically consistent with the strainstress curve.

Moreover, it is evident that the higher content of red mud, the more obvious the resistivity changes of solidified soil are. When $c_{R M}=0$, the change of the resistivity of solidified soils is the smallest. For example, when $C_{\mathrm{Cu}}=$ $0.5 \%$ the change rate of resistivity is less than $50 \%$ at this time. After adding red mud to the solidified soil, resistivity change rate can reach more than $70 \%$, which indicates the pressure sensitivity of solidified soil mixed with modified red mud increases significantly.

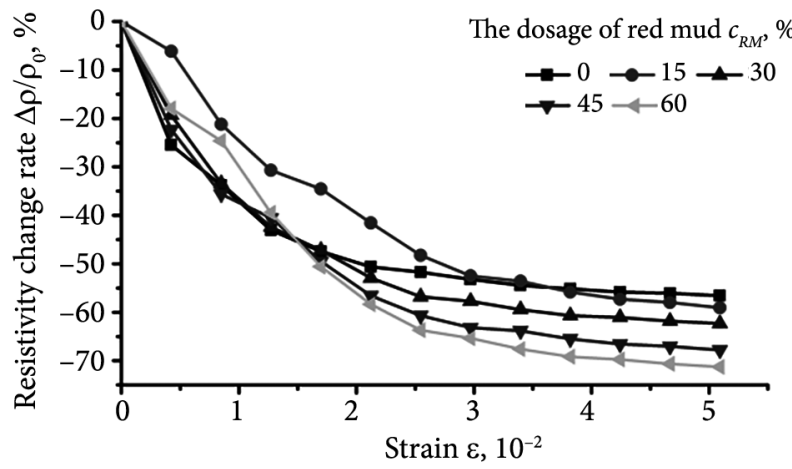

b) $C_{\mathrm{Cu}}=0.1 \%$



d) $C_{\mathrm{Cu}}=1 \%$

Figure 7. Curves of resistivity change rate and strain of solidified soil with different red mud contents on 28 days 


\subsection{Relationship between pressure sensitivity and copper content}

Figure 8 presents the curves of resistivity change rate and strain of solidified soil with different $\mathrm{Cu}^{2+}$ content after 28 days under different $C_{\mathrm{RM}}$. The rate of resistivity changes greatly with different copper contents. It is obvious that the influence of copper ion content can be divided into three cases: (1) $C_{\mathrm{Cu}}=0 \%$ (2) $C_{\mathrm{Cu}}=0.05-0.75 \%$ (3) $C_{\mathrm{Cu}}=$ $1-2.5 \%$ after adding red mud. When $C_{\mathrm{Cu}}=0 \%$, the resistivity change rate of solidified soil are in the range of $35-55 \%$. When $0.05 \% \leq C_{\mathrm{Cu}} \leq 0.75 \%$, the resistivity change rate of solidified soil can reach $65-80 \%$. However, the resistivity change rate of solidified soil are only $40-50 \%$ when $C_{\mathrm{Cu}}>0.75 \%$. It is seen that different contents of copper ion impose different degrees of chemical reaction on solidified soil, and not all of them exist in the form of free ions. All of these indicate that proper amount of copper can improve the pressure sensitivity of solidified soil, while excessive copper can reduce pressure sensitivity of solidified soil.

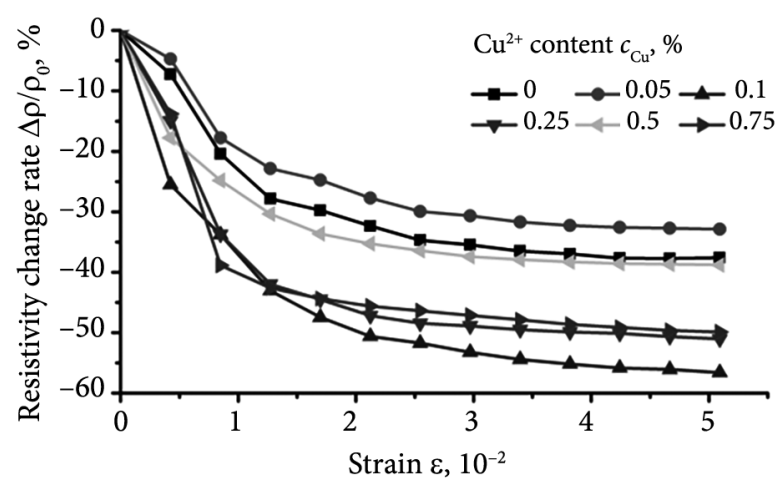

a) $C_{\mathrm{RM}}=0$

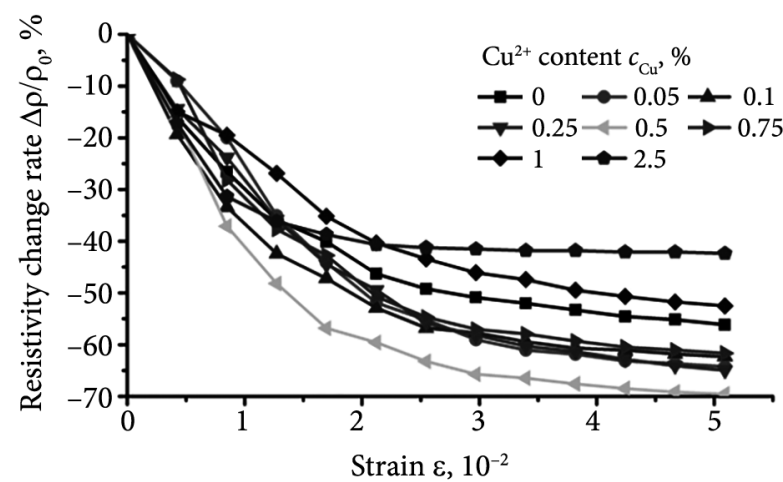

c) $C_{\mathrm{RM}}=30 \%$

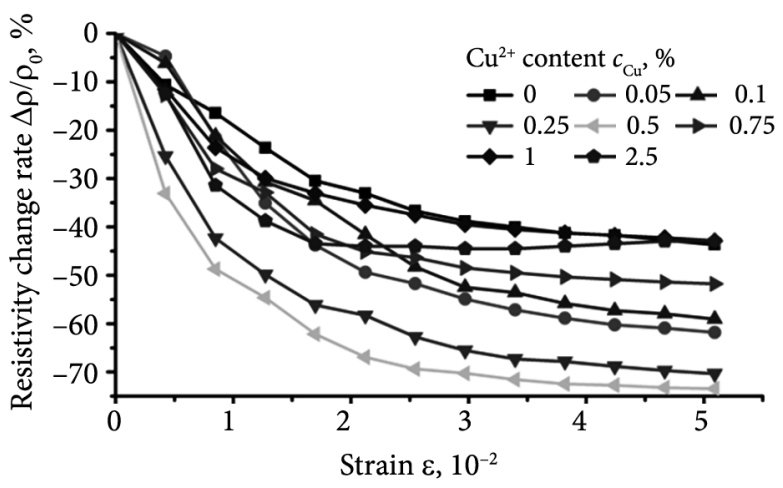

b) $C_{\mathrm{RM}}=15 \%$



d) $C_{\mathrm{RM}}=45 \%$

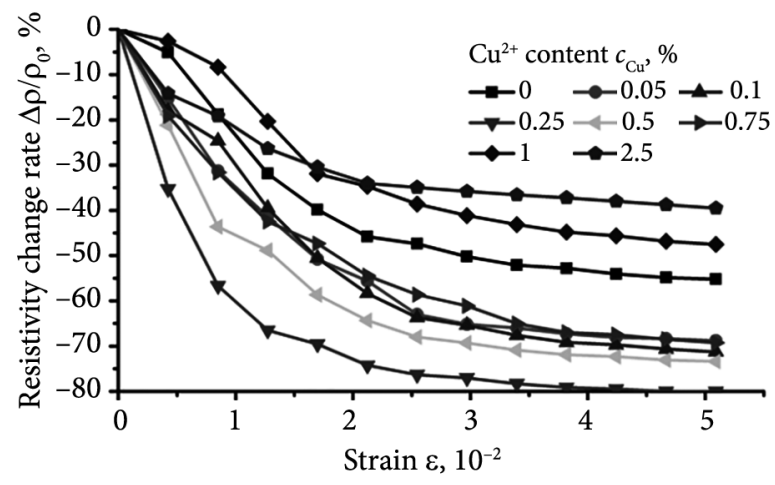

e) $C_{\mathrm{RM}}=60 \%$ 


\subsection{Relationship between pressure sensitivity and curing ages}

Figure 9 presents the relationship of resistivity change rate and strain of solidified soil at different curing ages. Generally the longer the age is, the more obvious the resistivity changes of solidified soil is. At Day 7, the change of resistivity of solidified soil is the smallest and within $40 \%$. At day 90 , the change of the resistivity of the solidified soil is almost the highest and reaches $60 \%$, which indicates that the long curing time improves the pressure sensitivity of the solidified soil.

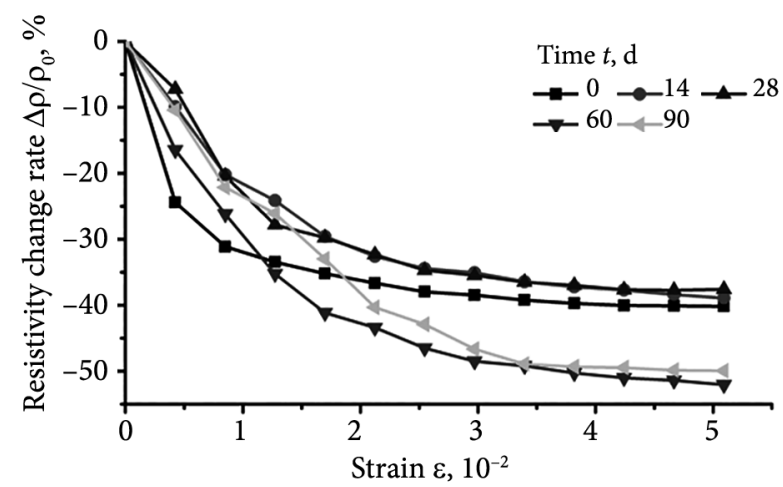

a) $C_{\mathrm{Cu}}=0$

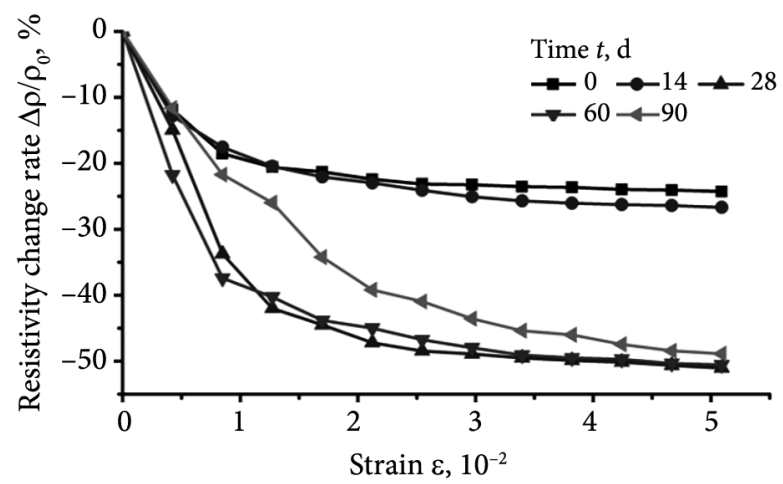

b) $C_{\mathrm{Cu}}=0.25 \%$

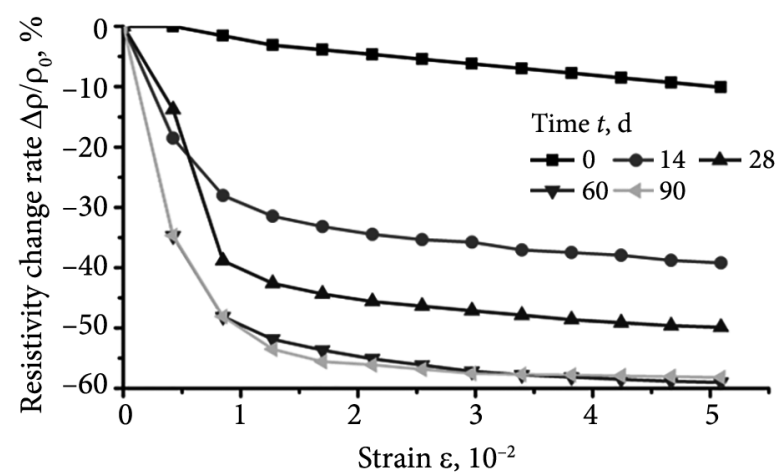

c) $C_{\mathrm{Cu}}=0.75 \%$

Figure 9. Relation of resistivity change rate and strain of solidified soil at different curing ages

\subsection{Mechanism analysis}

From the above analysis it can be seen that the resistivity change rate of solidified soil is closely related to the amount of red mud, the content of copper ion and the curing age. Conductive path of pore water, the iron oxide in the red mud, the conductive effect of the tunnel and the conductance percolation are main factors that affect the resistivity.

At the initial stage the internal pores are squeezed, the saturation degree increased, and the conduction channel narrowed, which results in the connection of some unconnected pore water to form a new conductive path, thus the resistivity decreases rapidly. When the peak stress is reached, the pore water in the test block reaches the capacity and the electrical resistivity reaches the lowest value. The pore water is interconnected in the new fissure as the specimen is further compressed. The newly produced cracks separate some conductive channels, and the resistivity change rate tends to be stable under the combined effect. The free copper ions and other ions in the pore water play the major role in electric conduction.

At the initial stage the contact or adjacent ferrite particles dispersed in the solidified soil and matrix became more compacted in the solidified soil. The ferrite particles as the initial conductive phase are squeezed into the cement matrix to reduce the potential barrier between the adjacent conductive particles. The interactions between the soil particles and powder particles is greatly increase, which creates possible connections between the pore water. More conductive pathways were formed to reduce resistivity. When the pressure continues to increase, the micro-cracks began to form, expand and connect. The stress concentration occurs at the cracks in the specimen. It is difficult for the ferrite particles to continue to be squeezed. The current compact state is maintained, thus the resistivity cannot be greatly reduced.

The conductive material as a potential barriers dispersed inside the solidified soil is blocked by hydration products, non-conductive solid materials and cracks. During the loading process, the potential barrier of the matrix gradually decreases. The distance between conductive materials at the solid state becomes smaller and the width of the barrier is reduced. The electrons and holes get sufficient energy to escape from the potential barrier and conduct each other in the conductive material, causing the internal tunnelling current to increase (Kim, Park, \& Lee, 2014; Binnemans, Jones, \& Blanpain, 2015; Ualles, Drummond, \& Saadaoui, 2008).

\section{Conclusions}

1) The resistivity of the solidified soil decreases rapidly as the stress increases. When the stress exceeds the peak value, the resistivity decreases slowly. The stress-strain relation of the solidified soil is similar to the relation of stress and change rate of resistivity. The change in resistivity can reflect the development of stress and strain. 
2) The resistivity change rate of the solidified soil decreases sharply and then tends to be stable with the increase of strain. The curve of the resistivity change rate has a gentle turning point, which is similar with the stressstrain curve.

3) The higher the red mud content is, the more obvious the resistivity change of solidified soil is, which indicates the modified red mud improves the pressure sensitivity of the solidified soils. A proper amount of copper can improve the pressure sensitivity of solidified soil, while excessive copper ions can reduce pressure sensitivity of solidified soil. A long curing time can also improve the pressure sensitivity of the solidified soil.

4) The pressure sensitivity of the solidified soils is closely related to the content of red mud, copper ions and the curing age. The conductivity of pore water, the iron oxide in the red mud, conductive effect of the tunnel and the conductance percolation are the main factors that affect the conductivity.

\section{Disclosure statement}

There are not any competing financial, professional or personal interests from other parties.

\section{References}

Abdulvaliyev, R., Akcil, A., \& Gladyshev, S. (2015). Gallium and vanadium extraction from red mud of Turkish alumina refinery plant: Hydrogarnet process. Hydrometallurgy, 157, 72-77. https://doi.org/10.1016/j.hydromet.2015.07.007

Alp, A., \& Goral, M. S. (2003). The influence of soda additive on the thermal properties of red mud. Journal of Thermal Analysis and Calorimetry, 73, 201-207. https://doi.org/10.1023/A:1025197927673

Binnemans, K., Jones, P. T., \& Blanpain, B. (2015). Towards zerowaste valorisation of rare-earth-containing industrial process residues: a critical review. Journal of Cleaner Production, 99, 17-38. https://doi.org/10.1016/j.jclepro.2015.02.089

Borra, C. R., Mermans, J., \& Blanpain, B. (2016). Selective recovery of rare earths from bauxite residue by combination of sulfation, roasting and leaching. Minerals Engineering, 92, 151-159. https://doi.org/10.1016/j.mineng.2016.03.002

Davris, P., Balomenos, E., \& Panias, D. (2016). Selective leaching of rare earth elements from bauxite residue (red mud), using a functionalized hydrophobic ionic liquid. Hydrometallurgy, $164,125-135$.

https://doi.org/10.1016/j.hydromet.2016.06.012
Gamaletsos, P. N., Godelitsas, A., Kasama, T. Kuzmin, A., Lagos, M., Mertzimekis, T., Göttlicher, J., Steininger, R., Xanthos, S., Pontikes, Y., Angelopoulos, G., Zarkadas, C., Komelkov, A., Tzamos, E., \& Filippidis, A. (2016). The role of nano-perovskite in the negligible thorium release in seawater from Greek bauxite residue (red mud). Scientific Reports, 6(21737), 1-12.

Kim, H. K., Park, L. S., \& Lee, H. K. (2014). Improved piezoresistive sensitivity and stability of CNT/cement mortar composites with low water-binder ratio. Composite Structures, 116, 713-719. https://doi.org/10.1016/j.compstruct.2014.06.007

Li, G. Y., Wang, P. M., \& Zhao, X. (2007). Pressure-sensitive properties and microstructure of carbon nanotube reinforced cement composites. Cement and Concrete Composites, 29(5), 377-382. https://doi.org/10.1016/j.cemconcomp.2006.12.011

Liu, B. W. (2016). Preparation and pressure sensitivity comparison of three new carbon - based cement composites were studied [D]. Beijing University of Civil Engineering and Architecture.

Lockwood, C. L., Mortimer, R. J., \& Stewart, D. I. (2014). Mobilisation of arsenic from bauxite residue (red mud) affected soils: effect of $\mathrm{pH}$ and redox conditions. Applied Geochemistry, 51, 268-277. https://doi.org/10.1016/j.apgeochem.2014.10.009

Ordóñez, S., Sastre, H., \& Díez, F. V. (2001). Hydrodechlorination of tetrachloroethylene over modified red mud: deactivation studies and kinetics. Applied Catalysis B: Environmental, 34, 213-226. https://doi.org/10.1016/S0926-3373(01)00217-X

Song, Z. W., Suo, C. X., Dong, X. Q., \& Chen, Y. F. (2018). Experimental study on solidification of $\mathrm{Cu}(\mathrm{II})$-contaminated soil using red mud with cement and $\mathrm{Ca}(\mathrm{OH})_{2}$. Materials Testing, 60, 184-190. https://doi.org/10.3139/120.111124

Sujana, M. G., Thakur, R. S., \& Acharya, B. C. (1996). Effect of calcination and physico-chemical properties of red mud. United States.

Sushil, S., \& Batra, V. S. (2012). Modification of red mud by acid treatment and its application for CO removal. Journal of Hazardous Materials, 203-204, 264-273. https://doi.org/10.1016/j.jhazmat.2011.12.007

Ualles, C., Drummond, C., \& Saadaoui, H. (2008). Solutions of negatively charged graphene sheets and ribbons. Journal of the American Chemical Society, 130, 15802-15804. https://doi.org/10.1021/ja808001a

Wansom, S., Kidner, N. J., \& Woo, L. Y. (2006). AC-impedanceresponse of multi-walled carbon nanotubes/cement composites. Cement and Concrete Composites, 28, 509-519. https://doi.org/10.1016/j.cemconcomp.2006.01.014

Zhao, R., Zhuang, Z., \& Jiyang, F. U. (2014). Research on pressure-sensitivity of cement morter with industrial waste. $M a$ terials Review, 28, 113-120. 